\title{
Resting and nesting in a small mammal: sleeping sites as a limiting resource for female grey mouse lemurs
}

\author{
Heike Lutermann $^{\mathrm{a}, \mathrm{b}, *}$, Luke Verburgt ${ }^{\mathrm{c}}$, Antje Rendigs ${ }^{\mathrm{a}, 1}$ \\ ${ }^{a}$ Institute of Zoology, School of Veterinary Medicine Hannover \\ ${ }^{\mathrm{b}}$ Mammal Research Institute, Department of Zoology and Entomology, University of Pretoria \\ ${ }^{\mathrm{c}}$ Department of Zoology and Entomology, University of Pretoria
}

\section{A R T I C L E I N F O}

\section{Article history:}

Received 16 September 2009

Initial acceptance 8 December 2009

Final acceptance 15 February 2010

Available online $\mathrm{xxx}$

MS. number: 09-00606

\section{Keywords:}

grey mouse lemur

limiting resource

Microcebus murinus

sleeping site

thermoregulation

\begin{abstract}
Animals spend a substantial proportion of their lives resting and consequently the choice of a sleeping site can dramatically affect an individual's fitness. Sleeping sites have been implicated in predator defence and thermoregulation and their distribution can affect breeding and social systems in small mammals. Sleeping sites may constitute a limiting resource for females which experience energetic constraints to breeding and require shelter for their young. Despite the potential importance of sleeping sites, exhaustive studies of the factors determining their usage patterns are limited to a small number of mammal groups. We investigated how seasonal changes in temperature or the presence of young shape sleeping site usage patterns in a small primate, the grey mouse lemur, Microcebus murinus. Females preferred tree holes over nests and open sites and the usage duration of a particular tree hole site was affected by the physical characteristics likely to affect its insulation properties. Furthermore, climate variables strongly affected sleeping site choices and nests were chosen more often than tree holes during the wet season. However, when young were present preferences shifted back to tree holes. Preferred tree species used as sleeping sites as well as the properties of tree holes were rare among trees in the study area suggesting that sleeping sites may indeed be a limiting resource for female grey mouse lemurs. Our results suggest that in the study species sleeping site choices are governed by thermoregulatory considerations and their limited availability could also account for the social grouping.
\end{abstract}

(c) 2010 The Association for the Study of Animal Behaviour. Published by Elsevier Ltd. All rights reserved.
Mammals spend a substantial proportion of their lives sleeping or resting (3-20 h/day, Elgar et al. 1988). A great diversity of sleeping sites have been described for mammals, from open sites in vegetation, natural shelters provided by trees or cavities, constructed shelters such as nests, dens and warrens to man-made structures (e.g. Roper 1992; Gibbons \& Lindenmayer 2002; Kunz \& Lumsden 2003). As a consequence of the long time spent resting, the choice of sleeping or resting site can have important effects on individual survival and fitness (e.g. Soderquist 1993; Kunz \& Lumsden 2003; Fisher \& Wiebe 2006).

Sleeping sites can provide substantial thermoregulatory benefits for an individual since they afford shelter from adverse weather conditions and buffer against variation in ambient temperature and humidity (Schmid 1998; Speakman et al. 1999; Roper et al. 2001; Sedgeley 2001; Gibbons \& Lindenmayer 2002). This is particularly

\footnotetext{
* Correspondence: H. Lutermann, Mammal Research Institute, Department of Zoology and Entomology, University of Pretoria, Pretoria 0002, South Africa.

E-mail address: hlutermann@zoology.up.ac.za (H. Lutermann).

1 A. Rendigs is at the Institute of Zoology, School of Veterinary Medicine Hannover, Bünteweg 17, 30559 Hannover, Germany.
}

important for small mammals that experience high heat loss as a result of an unfavourable volume-to-surface ratio (SchmidtNielsen 1997). This physiological constraint has favoured the use of torpor in small mammals to reduce the energetic costs of maintaining a high body temperature during cold exposure (Geiser 1994). The abundance of suitable sleeping sites as well as their proximity to food resources can further shape shelter use (e.g. Day \& Elwood 1999; Sedgeley \& O'Donnell 1999; Martin \& Martin 2007). In addition, the availability of suitable sleeping sites can limit population density and affect a species' space use and social interactions (Du Plessis 1992; Doncaster \& Woodroffe 1993; Chaverri et al. 2007b; Martin \& Martin 2007; Walker et al. 2007; Kerth 2008).

The fitness of female mammals is limited by the availability of resources that affect reproduction (Emlen \& Oring 1977; CluttonBrock 1989). Consequently, female spacing patterns reflect the distribution of such limiting resources. Food is the most commonly cited ecological factor affecting space use of females (e.g. Ostfeld 1985, 1990; van Schaik 1989; Sterck et al. 1997; Maher \& Lott 2000). However, other factors, such as shelter, may shape female spatial distribution as the thermoregulatory capacities of shelters can impact on the energy available to females for reproduction. In 
addition, female mammals require well-insulated and protected sites for dependent young (Soderquist 1993; Radespiel et al. 1998; Henner et al. 2004; Chaverri et al. 2007a). The importance of this resource for female mammals is illustrated in a study of bobucks, Trichosurus cunninghami (Martin \& Martin 2007) where females increased their home range size by three times in habitats where den trees were rare compared to habitats were they were common, even though food abundance was comparable between the sites.

The use of shelters and roosts has featured prominently in studies of bats and they are considered key resources determining their ecology, reproductive success, social and mating system (reviewed in Kunz 1982; Kunz \& Lumsden 2003). In comparison, studies in other mammal groups are less numerous and often restricted to comparing usage patterns with availability (e.g. Di Bitteti et al. 2000; Henner et al. 2004; Lindenmayer et al. 2004; but see Rogers et al. 2003; Walker et al. 2007). The grey mouse lemur, Microcebus murinus, shares a number of traits with bats, including their nocturnal lifestyle and the solitary foraging habits as well as their reliance on torpor. Hence, sleeping sites may be of similar importance as they are in bats.

Mouse lemurs can make extensive use of torpor during the cold period of the year (Schmid \& Speakman 2000) and achieve substantial energy savings from torpor (Schmid 2000). Sleeping sites with good insulation properties, such as tree holes, can delay the onset of active arousal from torpor in grey mouse lemurs and thereby provide additional energy savings (Schmid 1998). The sleeping site trees available and the population dynamics of grey mouse lemurs differ markedly between primary and secondary forests (Ganzhorn \& Schmid 1998) with lower population densities and recapture rates for the latter. Ganzhorn \& Schmid (1998) suggested that this is related to higher radiation in the secondary forest and consequently a lower incidence of torpor. The resulting higher energy demands during winter when food availability is reduced may lead to higher mortality rates.

Thermoregulation is likely to affect sleeping site use in female grey mouse lemurs. However, if sleeping sites are a limiting resource for females with dependent offspring this may also explain the sex-specific differences in sleeping site usage patterns found in grey mouse lemurs. Previous studies have shown that males tend to use less protected sleeping sites, often resting in open vegetation, and changing their sleeping sites more frequently than females in this species (Radespiel et al. 1998; Lahann 2008). As such sites are unsuitable for raising offspring, females may be forced to form groups to monopolize suitable sleeping sites. Thus, sleeping sites have the potential to affect female fitness either directly through female survival or indirectly through increased offspring survival.

The aim of the current study was to assess the importance of thermoregulatory demands on sleeping site use in female grey mouse lemurs. Such demands can either act directly on females during periods of food scarcity, when maintaining low body temperatures in well-insulated sleeping sites provides energy savings, or indirectly as the altricial offspring require well-insulated shelter. We hypothesized that energetic constraints experienced by females during the dry season would result in a higher probability of using insulated sleeping sites (i.e. tree holes that are likely to facilitate extended torpor bouts) during this period while such preferences should be less pronounced during the wet season. We predicted a similar preference during the presence of offspring that require insulation. Furthermore, we tested the hypothesis that sleeping sites constitute a limiting resource for females in this species. This was achieved by (1) describing the characteristics and usage patterns of sleeping sites in female grey mouse lemurs during both dry and wet seasons, (2) evaluating the influence of climatic conditions and reproduction on usage patterns and (3) comparing the vegetation characteristics of sleeping sites with the general vegetation characteristics of the study area.

\section{METHODS}

\section{Study Site}

The distribution of grey mouse lemurs (family Cheirogaleidae, comprising the smallest living primates) stretches along the west coast of Madagascar from the evergreen rainforests around Tolagnaro at the southern tip to the Ankarafantsika National Park in the northwest of the island (Martin 1973; Tattersall 1982; Mittermeier et al. 2009). The study was conducted in a 30 ha plot (Jardin Botanique A, JBA) of dry deciduous forest in the Reserve Forestière d'Ampijoroa $\left(46^{\circ} 48^{\prime} \mathrm{E}, 16^{\circ} 19^{\prime} \mathrm{S}\right)$ about $110 \mathrm{~km}$ southeast of Majahanga, northwestern Madagascar at the northernmost range of the grey mouse lemur distribution. Female grey mouse lemurs in the study area do not exhibit seasonal torpor reported for other populations (Schmelting et al. 2000) and this may be related to the quality of the sleeping sites available.

\section{Radiotelemetry and Sleeping Site Characteristics}

Field data were collected from July 1998 to April 1999 (hereafter referred to as 1998), and from August 1999 to April 2000 (hereafter referred to as 1999). We routinely trapped mouse lemurs 3 nights a month by placing 90 Sherman traps (HB Sherman Traps, Inc., Tallahassee, FL, U.S.A.) on the intersections of a rectangular trail system. Traps were baited with banana at dusk and collected early the following morning. Captured individuals were only briefly removed from the traps for processing (i.e. sexing, weighing) and spent the remainder of the time until release in the shaded traps. The animals were released at dusk at their respective capture sites. During periods when females had dependent offspring traps were checked during the night of capture and animals were released $2 \mathrm{~h}$ prior to dawn to minimize separation of nursing mothers from their young.

A total of 148 individuals (94 males, 52 females and two juveniles of unknown sex) were caught throughout the study. Each captured individual was marked with a transponder injected subcutaneously (Trovan Small Animal Marking System; Telinject, Römerberg, Germany). In total, 26 individual female mouse lemurs were radiocollared (TW4-button cell tags, Biotrack, Wareham, U.K.), 16 in 1998 and 17 in 1999, with seven carrying transmitters in both years. Transmitters weighed between 2 and $3 \mathrm{~g}$ which corresponded to $3-5.5 \%$ of the animals' body mass and had a life expectancy between 3 and 5 months but occasionally failed earlier. If possible, collars were replaced when batteries failed. Collars were removed from all study animals captured at the end of each study year. Permission for the study was obtained from the Commission Tripartite of the Malagasy government, the Department des Eaux et Forêts (DEF) and the Association pour la Gestion des Aires Protégées (ANGAP).

Day sleeping sites were located on 5-7 days per week with a TR-4 receiver with a RA-14K antenna (Telonics Inc., Impala, AZ, U.S.A.). When possible, the sleeping site location was confirmed by visual sighting and/or with a transponder reading device. Sleeping sites were marked with coloured tape on first encounter and later permanently marked with a metal tag with date of first location and animal identity imprinted. We classified sleeping sites into the following three categories: (1) tree holes: this comprised cavities in tree trunks and branches; (2) (leaf) nests: spheres built from leaves incorporating supporting structures such as branches, abandoned birds' nests and plant creepers; and (3) open sites: usually located in branches and occasionally on the ground without any visual 
cover. Although we did not observe nest building, it has been described for golden-brown mouse lemurs, Microcebus ravelobensis (Thorén et al. 2010). Thus, it is highly likely that females built leaf nests themselves, as nests were usually built from fresh leaves originating from tree species other than the one they were found in. In addition, on at least one confirmed occasion the nest was not present in the recorded location on the previous day (B. Schmelting, personal communication). Nests are usually located in the lower canopy and have probably only limited durability because of the withering of the leaves.

Physical factors such as the height of a sleeping site sometimes limited our access to a site; however, where possible we measured a number of physical parameters for each site. The trees in which the site was located were classified as alive or dead and the diameter at breast height (DBH) of the sleeping site was measured. The height, number and location of entrances with respect to the sleeping site (i.e. above, below or on the side of the site) were recorded. We calculated entrance size as the product of the height and width of the entrance and wall thickness as the difference between the inner diameter of the tree hole and the outer diameter of the tree at the entrance level. Depth of a hole was determined by inserting a folding rule until the bottom of the hole was reached. The cavity volume of tree holes was determined using the volume formula for a cylindrical body: $r^{2} \times \pi \times h(r$ : inner radius; $h$ : height of the hole). All these parameters were measured when sleeping sites were vacant. In addition the plant species used as sleeping site were identified (see below).

\section{Climatic Conditions and the Presence of Offspring}

We obtained climate data for the study period from a weather station located about $1 \mathrm{~km}$ from the study plot maintained by the Durrell Wildlife Conservation Trust, Jersey, Channel Islands, U.K. Data obtained, summarized in Fig. 1, included daily minimum $\left(T_{\min }\right)$ and maximum temperature $\left(T_{\max }\right)$ as well as daily precipitation for the entire study period. The climatic conditions could be clearly distinguished between dry (rainfall: $1.86 \pm 7.89 \mathrm{~mm}$ ) and wet seasons (rainfall: $10.25 \pm 19.31 \mathrm{~mm} ; t=6.01, P<0.0001$ ) with the latter being characterized by daily rainfall and an associated decrease in the range of temperatures measured ( $T_{\min }$ : $19.24 \pm 2.81^{\circ} \mathrm{C}$ versus $21.62 \pm 1.17{ }^{\circ} \mathrm{C} ; t=9.87, P<0.0001 ; T_{\max }$ : $35.6 \pm 2.79{ }^{\circ} \mathrm{C}$ versus $\left.33.16 \pm 2.73{ }^{\circ} \mathrm{C} ; t=8.50, P<0.0001\right)$.

All radiocollared females were closely monitored during their anticipated time of delivery and females were located repeatedly during their activity period. The birth of a litter was identified when females failed to resume their usual foraging activity and remained

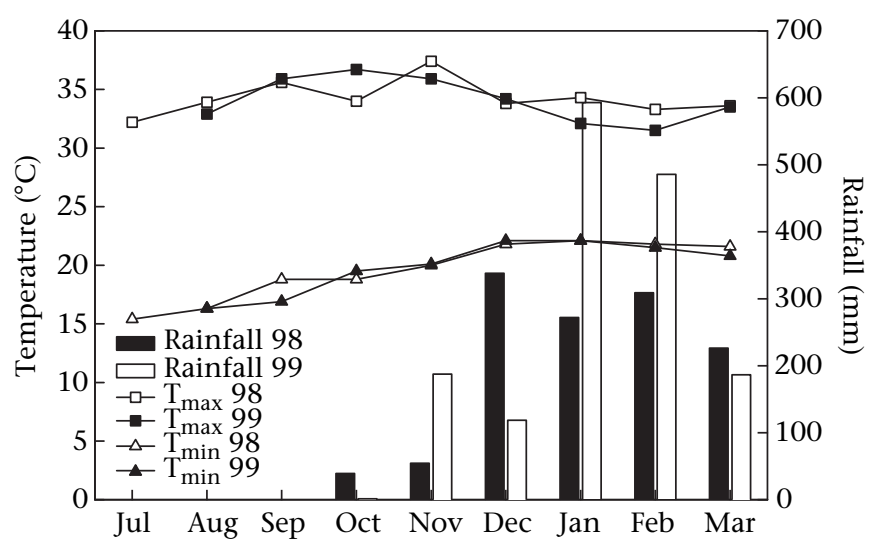

Figure 1. Average daily minimum and maximum temperatures and total rainfall per month measured in the study area during 1998 (98) and 1999 (99). in their sleeping sites for extended periods during the night which never occurred when no offspring was present. Regular observations at sleeping sites were continued and the presence of offspring could usually be confirmed visually within days of the delivery.

\section{Characteristics of Reference Plot Vegetation}

To assess the availability of sleeping sites we counted all trees with DBH in four size classes ( $<5 \mathrm{~cm}, 5-10 \mathrm{~cm}, 11-20 \mathrm{~cm},>20 \mathrm{~cm}$ ) in $5 \times 5 \mathrm{~m}$ quadrats at 36 trail intersections in the ranging area of our study animals. Quadrats were placed at a distance of $\geq 3 \mathrm{~m}$ from the trails to reduce edge effects. In addition, all dead stumps and trees in the plots were recorded irrespective of the presence of tree holes. Owing to logistical limitations, neither live nor dead trees were assessed for the presence of holes that might potentially offer sleeping sites. All trees counted in a plot were identified and individually marked with a plastic tag.

\section{Statistical Analysis}

For the statistical analysis investigating factors affecting sleeping site selection, we used only the first complete observation for a sleeping site since multiple observations were recorded for individuals and for sleeping sites. Using the first observation for a sleeping site may overinflate the effects of causative agents responsible for a change in sleeping site selection and therefore provides greater insight into environmental factors that may be responsible for influencing decisions on sleeping site choice. Sleeping site data were pooled between years since we had no a priori reason to suspect any difference in the magnitude of environmental factors between two successive years acting on sleeping site selection. We omitted open sleeping sites from the data set since only 14 unique records used by 11 different individuals were obtained with all explanatory variables recorded.

To determine which of six environmental variables best predicted the utilization of the two sleeping site types, we carried out backward stepwise logistic regression analysis using the PROC LOGISTIC procedure of the SAS version 9.1 statistics package (SAS Institute, Cary, NC, U.S.A.). Variables remained in the model if $P<0.05$. The contribution of individual variables to each model was assessed with Wald's chi-square statistic. We assessed overall model accuracy based on a logistic cut point of 0.5 to classify sleeping site type. Initially, one categorical (tree status) and five continuous variables (DBH, tree height, rainfall, $T_{\min }$ and $T_{\max }$ ) were subjected to stepwise logistic regression to determine their predictive power for the two sleeping site types from 173 unique observations (tree hole: $N=126$; nest: $N=47$ ). Tree height was included in the analysis because no relationship with DBH was found $\left(F_{1,172}=0.40, R^{2}<0.01, P=0.53\right)$. Similarly, no relationship between $T_{\min }$ and $T_{\max }$ was found $\left(F_{1,172}=0.04, R^{2}<0.01, P=0.85\right)$. Rainfall was significantly related to both $T_{\min }$ and $T_{\max }\left(F_{1,172}>9.31\right.$, $R^{2}>0.05, P<0.003$ ) but this was due to 121 observations where no rain occurred (i.e. $0 \mathrm{~mm}$ ). When the analysis was restricted to observations where rain occurred (rainfall $>0 \mathrm{~mm}$ ) there was no relationship between rainfall and either $T_{\min }\left(F_{1,51}=0.087\right.$, $\left.R^{2}<0.001, P=0.77\right)$ or $T_{\max }\left(F_{1,51}=1.74, R^{2}=0.014, P=0.19\right)$ which justified the inclusion of rainfall in the logistic regression. This analysis aimed to identify whether thermoregulatory properties of a sleeping site and/or thermoregulatory demands as a result of climatic factors govern sleeping site choice in grey mouse lemur females.

The presence of dependent offspring could place thermoregulatory constraints on females in this species irrespective of those experienced by the females themselves and this could modify sleeping site preferences. Thus, we repeated the logistic regression 
analysis but included the presence of dependent offspring as a categorical variable to assess the relative magnitude of this parameter in conjunction with the environmental parameters.

All statistical tests were conducted with $\alpha=0.05$. However, the $\alpha$ value of post hoc tests was adjusted with a sequential Bonferroni correction for multiple comparisons (Rice 1989). Values reported are mean \pm SEM unless specified otherwise.

\section{RESULTS}

\section{Sleeping Site Characteristics}

Individual females were located in their sleeping sites on 8-189 days (median: 161.5 days) in 1998 and on 13-164 days (median: 88.0 days) during 1999. We recorded a total of 173 individual sleeping sites in 1998 and 136 in 1999 with 12 being used in both years. We could not unequivocally identify 32 sites in 1998 and seven sites in 1999 as sleeping sites. The most common type of sleeping site used by female grey mouse lemurs comprised tree holes. Of the identified sites, 102 in 1998 and 90 in 1999 were tree holes. Other types were used less frequently (nest: $1998=44$, $1999=41$; open: $1998=26,1999=5$ ). The characteristics of the sleeping sites found are presented in Table 1.

\section{Sleeping Site Preference and Fidelity}

To determine sleeping site preferences we enumerated the number of nights on which each individual used each of the three sleeping site types. Since individuals were not observed for an equal number of nights (range 8-348), we calculated the proportional utilization of each sleeping site for each individual. A significant difference in sleeping site utilization was found (Friedman ANOVA: $\chi_{2}^{2}=36.0, N=22, P<0.001$ ). Post hoc analysis (Wilcoxon signed-ranks test) revealed that tree holes were used significantly more than either nests $(Z=3.78, P<0.001)$ or open sites $(Z=4.11, P<0.001)$, while nests were used significantly more often than open sites $(Z=2.51, P<0.05)$.

Sleeping site fidelity was calculated for each individual and each sleeping site type as the number of consecutive nights spent in a particular sleeping site. These values were then grouped by sleeping site type and a mean value per individual was calculated for each sleeping site type. Twelve individuals were observed in all three different sleeping site types. We subjected these data to a Friedman ANOVA which showed a significant difference in the consecutive usage between sleeping site types $\left(\chi_{2}^{2}=19.48, N=12\right.$, $P<0.0001$ ). Post hoc analysis (Wilcoxon signed-ranks test) showed that this difference was due to tree holes being used a greater number of consecutive days than either nests or open sites $(Z=3.06, P<0.01)$. Since tree holes appeared to be the preferred sleeping sites we further focused on evaluating the factors that influence the choice of a tree hole as a sleeping site.

\section{Physical Properties and Sleeping Site Selection}

We tested for preferences for particular characteristics of tree holes by calculating the total number of nights (log transformed for normality) that a tree hole was occupied by at least one of the collared females during the study period. Forward stepwise multiple regression analysis was used to determine the factors significantly contributing towards the preference for tree holes. Five variables were entered into the regression analysis (DBH, wall thickness, entrance height, surface area of entrance, hole volume) where the latter two variables required log transformation before data were normally distributed. The variables entrance height, hole volume and wall thickness contributed significantly to the prediction of sleeping site preference $\left(F_{4,53}=5.17, R^{2}=0.28, N=58\right.$, $P=0.001$; Table 2).

\section{Effects of Thermoregulatory Demands on Sleeping Site Selection}

Tree status, rainfall, $T_{\min }, T_{\max }$ and $\mathrm{DBH}$ contributed significantly to explain sleeping site selection (Table 3, Model 1). The probability of using a tree hole increased with decreasing $T_{\min }$ and increasing $T_{\max }$ and DBH (Fig. 2). Rainfall significantly decreased the probability of a tree hole being used as a sleeping site $(W=4.02$, $P=0.045$ ). When offspring presence was included as a parameter in the model, rainfall was no longer retained as a significant parameter; however, the probability of using a tree hole increased significantly with the presence of offspring (Table 3, Model 2).

\section{Availability of Sleeping Sites}

Since tree holes were preferred by female grey mouse lemurs this analysis was restricted to parameters of trees containing such tree holes. A significant difference was found between the DBH of trees utilized and the available trees $\left(\chi_{2}^{2}=394.8, P<0.0001\right.$; Fig. 3a). For trees with tree holes used, $64.3 \%$ belonged to the largest DBH category even though these trees represented only $5.2 \%$ of the trees in the study area. Furthermore, a significant difference between the number of dead trees utilized as sleeping sites was found compared to the number of dead trees available in the area (Yates-corrected $\chi_{1}^{2}=284.8, P<0.0001$; Fig. 3b). In the study plot, $8.6 \%$ of the trees were dead but $66.7 \%$ of the trees in which tree holes were used were dead.

The tree species used for tree hole sleeping sites were from 22 plant families of 30 genera and a minimum of 42 species. From the vegetation plots we identified 42 tree families $(N=1156)$; however, only 17 of these were utilized. We excluded plant families from the analysis that were either used or observed less than five times, which reduced the analysis to six families. Utilization of the remaining plant families deviated significantly from their distribution in the study area $\left(\chi_{2}^{2}=86.9, P<0.0001\right.$; Fig. $\left.3 c\right)$ with three tree families used more often than expected by their abundance

Table 1

Descriptive statistics for sleeping sites found in this study

\begin{tabular}{|c|c|c|c|}
\hline & Tree hole & Nest & Open \\
\hline Diameter at breast height $(\mathrm{cm})$ & $13.4 \pm 7.2(102)$ & $8.2 \pm 4.1(43)$ & $9.3 \pm 5.6(16)$ \\
\hline Entrance height $(\mathrm{cm})$ & $132.2 \pm 127.1(110)$ & $356.7 \pm 71.5(51)$ & $277.7 \pm 90.0(31)$ \\
\hline \% Entrance uncovered & $91.5(106)$ & - & - \\
\hline No. of entrances & $1.2 \pm 0.4(105)$ & - & - \\
\hline$\%$ Entrance above & $83.8(105)$ & - & - \\
\hline Entrance size $\left(\mathrm{cm}^{3}\right)$ & $62.0 \pm 69.9(91)$ & - & - \\
\hline Cavity volume $\left(\mathrm{cm}^{3}\right)$ & $1203.9 \pm 1155.2(66)$ & - & - \\
\hline Wall thickness (cm) & $4.6 \pm 3.5(75)$ & - & - \\
\hline$\%$ Alive & $31.9(113)$ & $100(66)$ & $100(31)$ \\
\hline
\end{tabular}

Mean \pm SD. Sample sizes are given in parentheses. 
Table 2

Factors contributing significantly to the prediction of tree hole preference as determined by forward stepwise multiple regression

\begin{tabular}{lllll}
\hline Factors & $\beta$ & $B$ & $t_{53}$ & $P$ \\
\hline Entrance height & $0.552 \pm 0.153$ & $0.003 \pm 0.001$ & 3.600 & 0.001 \\
Log hole volume & $0.390 \pm 0.136$ & $0.534 \pm 0.186$ & 2.875 & 0.006 \\
Wall thickness & $0.521 \pm 0.229$ & $0.091 \pm 0.040$ & 2.276 & 0.027 \\
\hline
\end{tabular}

(i.e. Euphorbiaceae, Fabaceae and Loganiaceae) while the other three were used less than expected (i.e. Ebeneaceae, Oleaceae and Rubiaceae).

\section{DISCUSSION}

\section{Sleeping Site Characteristics and Selection Pressure}

Females in our study showed a strong preference for sleeping sites in tree holes which are thought to be superior to the other types with respect to both thermoregulatory needs and predation (Kunz 1982; Schmid 1998; Gibbons \& Lindenmayer 2002; Kunz \& Lumsden 2003). At the same time, entrance height for these tree holes was markedly lower than for nests or open sites. It has been suggested for cavity-nesting birds and bats that the risk of predation decreases with increasing entrance heights (Sedgeley 2001; Fisher \& Wiebe 2006). Similarly, there is evidence that tree holes experience lower temperatures when located at greater entrance heights (Isaac et al. 2008) and thus allow for larger energy savings as the animals can remain heterothermic for longer periods. It is thus surprising that sleeping sites in tree holes have substantially lower entrance heights than either nests or open sites. However, the results of the multiple regression analysis indicate that female grey mouse lemurs indeed prefer tree holes with greater entrance heights and such holes are used for more extended periods of time. They may be forced to use sites at lower heights because of the physical properties of the tree harbouring the site. Trees are usually larger at the base and decrease in diameter with increasing height. Thus, holes of appropriate size are more likely to be found at the base of trees than at greater heights and this could account for the observed pattern (Gibbons \& Lindenmayer 2002). Since nests and open sites do not pose similar physical constraints their height is more likely to correspond to that preferred by the animals. Other features recorded for tree holes in our study such as the number and size of entrances and the lack of vegetation cover could also provide benefits related to either thermoregulation or predator protection (Kunz 1982; Kunz \& Lumsden 2003). However, it is

Table 3

Environmental and social parameters contributing significantly to the prediction of sleeping site type as determined by logistic regression

\begin{tabular}{lll}
\hline Parameter & Model 1 & Model 2 \\
\hline Tree status (alive/dead) & $9.69^{* *}$ & $11.68^{* * *}$ \\
Rainfall & $4.02^{*}$ & Removed \\
Offspring presence & - & $5.88^{*}$ \\
$T_{\min }$ & $5.48^{*}$ & $10.06^{* *}$ \\
$T_{\max }$ & $9.09^{* *}$ & $13.17^{* * *}$ \\
Diameter at breast height & $14.16^{* * *}$ & $15.79^{* * *}$ \\
Observations $(N)$ & 173 & 172 \\
Classification accuracy (\%) & 82.7 & 82.6 \\
Akaike information criterion (AIC) & 136.4 & 134.7 \\
\hline
\end{tabular}

Values are Wald's chi-square statistics. Model 1 included only environmental parameters (offspring presence omitted) while Model 2 additionally included the presence of offspring. When the presence of offspring was entered into the model the effect of rainfall was no longer significant and rainfall was therefore removed from the model.

${ }^{*} P<0.05 ;{ }^{* *} P<0.01$; ${ }^{* * *} P<0.001$. difficult to distinguish between the effects of predation and thermoregulation as selective forces in our study and predation was not assessed directly. We therefore focus on effects that could directly be related to thermoregulatory needs represented by climate variables and the presence of dependent young.

\section{Thermoregulatory Demands and Sleeping Sites}

Our results show that female grey mouse lemurs show a shift from tree holes to sites such as nests and open sites that provide fewer thermoregulatory advantages with the onset of regular heavy rainfall. Seasonal variation in usage patterns of sleeping sites has been reported for bats as well as marsupials (e.g. Cockburn \& Lazenby-Cohen 1992; Kerth et al. 2001) but not for lemurs, probably a result of the short-term studies that have previously been conducted in this group (Radespiel et al. 1998, 2003; Lahann 2008). The shift in preferences observed in our study mirrors the change in temperature fluctuations between the two seasons and the range of temperatures experienced was significantly smaller during the rainy than the dry season at our study site. Similar shifts in preferences for sleeping site characteristics linked to temperature changes have been reported for birds (e.g. Ardia et al. 2006; Velky et al. 2010). It is well documented that tree holes can buffer against temperature fluctuations (Schmid 1998; Sedgeley 2001; Willis \& Brigham 2007; Isaac et al. 2008) and the change in sleeping site usage that we observed may thus indicate the lower thermoregulatory constraints experienced by the females during the wet season. During the dry season, the lower minimum temperatures, greater temperature fluctuations and low food availability mean that females must expend more energy to maintain a high body temperature. They can avoid this by seeking sleeping sites that sustain extended torpor bouts such as tree holes. Females prefer tree holes (preferentially those with entrances located high and therefore colder) as these minimize fluctuations in temperature and allow them to remain heterothermic for longer periods (Schmid 1998). During the wet season, food availability increases dramatically and thus energetic limitations are lifted. If females have offspring during the dry season they seek out tree holes because these are well insulated and protect the young from temperature fluctuations.

The observed preference for tree holes with thick walls and large volumes, both factors that increase the insulation capacities of tree holes (Kunz 1982; Sedgeley 2001; Gibbons \& Lindenmayer 2002; Kunz \& Lumsden 2003), further supports the hypothesis that thermoregulatory needs are largely responsible for the choice of sleeping site in the study animals. Furthermore, mouse lemurs have only been observed to enter torpor during the dry but not the wet season (Schmid \& Speakman 2000). However, the majority of tree holes were located in dead trees that are known to have lower insulation capacities than live trees (Kunz 1982; Schmid 1998; Gibbons \& Lindenmayer 2002; Kunz \& Lumsden 2003) and their frequent use appears contrary to thermoregulatory arguments. The predominant use of dead trees has also been shown for a number of bats and other small mammals (Sedgeley \& O'Donnell 1999 and references therein; Gibbons \& Lindenmayer 2002) and it has been suggested that this may rather be related to the higher probability of dead trees harbouring such holes than to thermoregulatory considerations alone.

Although we did not find a direct correlation between rainfall and temperatures, rainfall could have contributed to the change in temperature fluctuation observed in our study and thus be indirectly responsible for this change in the usage patterns observed. In addition, rainfall may also be directly responsible for the observed shift from tree holes to nests and open sites. The majority of tree holes had entrances at the top of the cavities and, although not 

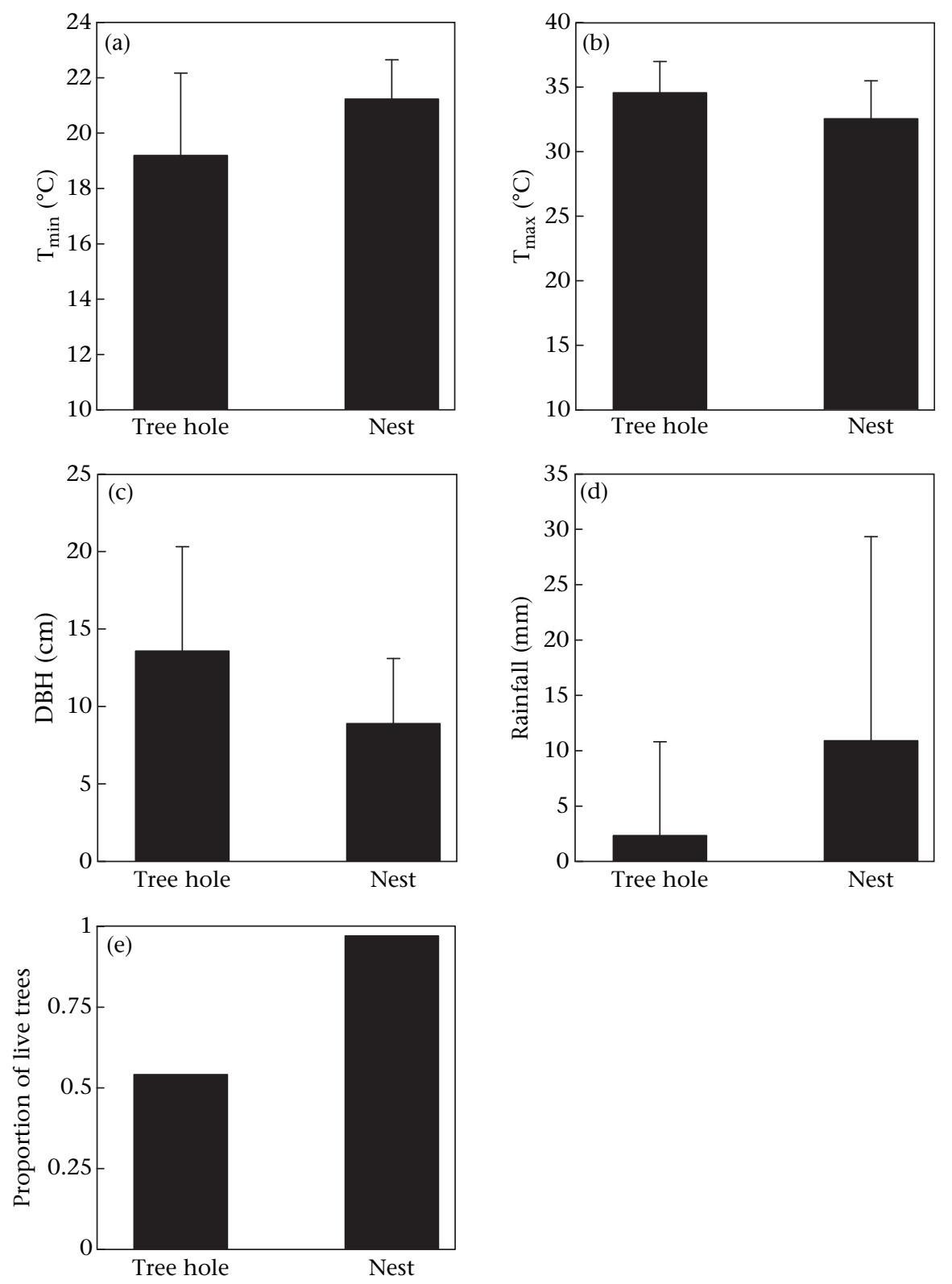

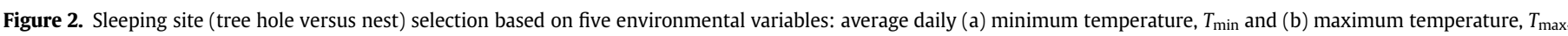

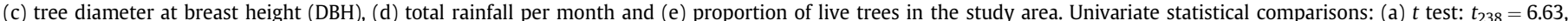

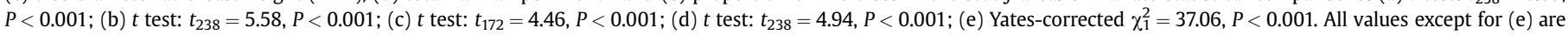
mean \pm SEM.

quantified in this study, a number of extensively used tree holes were rendered unusable after rainfall as they were flooded with water.

Although thermoregulation may be of minor importance for females during the wet season, their altricial offspring require wellinsulated sites. Thus, female grey mouse lemurs prefer tree holes when dependent offspring are present. Similar thermoregulatory considerations have been shown to govern sleeping site choices in marsupials (Soderquist 1993). Since reproduction is highly synchronized in the study population and the first litter coincides with the change in seasonal rainfall (Schmelting et al. 2000) this could explain the change in significance of the variable rainfall when the presence of offspring was included in the analysis. Preference for warmer or better insulated sleeping sites during lactation has previously been reported for bats, which often resume torpor and seek cooler sites after weaning their offspring (e.g. Lausen \& Barclay 2003; Chaverri et al. 2007a; Solick \& Barclay 2007).

\section{Sleeping Sites as Limiting Resource}

Grey mouse lemur females used holes in trees with large DBH more than 10 times as often as could be expected by their availability in the study area. At the same time holes were almost eight times more likely to be located in dead trees than could be expected from their availability. It is likely that these observations are linked to the increased likelihood of a cavity developing with both increasing decay of the tree and tree diameter (Gibbons \& Lindenmayer 2002). The highly skewed use of sleeping sites suggests that sleeping site trees are restricted in the study area and 

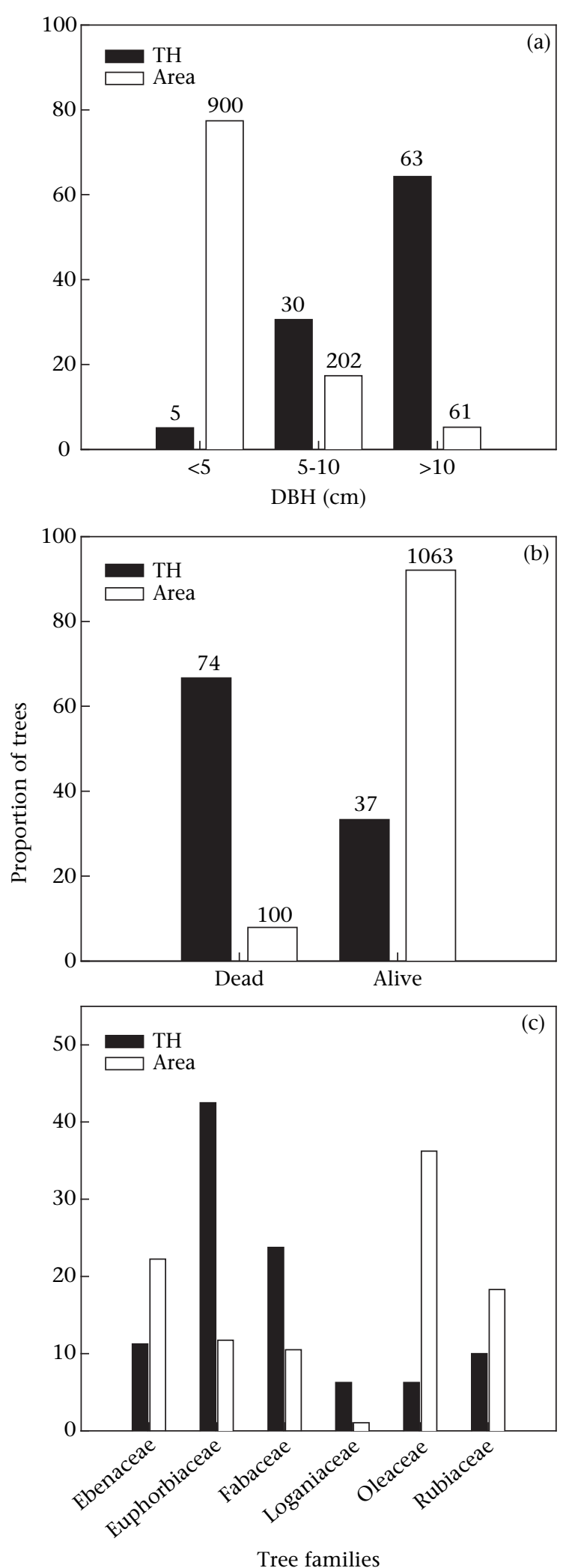

Figure 3. Percentage of tree hole sleeping site trees $(\mathrm{TH})$ and trees in the general area (Area) (a) in three size categories (diameter at breast height, DBH), (b) that are dead or alive and (c) that belong to six different families. The percentages for $\mathrm{TH}$ and Area trees were both calculated as the number of trees per category divided by the sum of all the trees across categories. Numbers above bars are sample sizes per category. may thus represent a limiting resource for female grey mouse lemurs as has been reported for other mammals (e.g. Du Plessis 1992; Doncaster \& Woodroffe 1993; Martin \& Martin 2007; Walker et al. 2007). The importance of large trees for the study species is further indicated by the uneven distribution of grey mouse lemurs in the study area that has previously been linked to vegetation features such as a lack of large trees and cover with plant creepers (Rendigs et al. 2003). Grey mouse lemurs do not occur in areas where large trees are lacking but plant creepers are common, whereas the golden-brown mouse lemur often uses unprotected sites in branches and plant creepers (Radespiel et al. 2003) and is commonly found in areas where grey mouse lemurs are absent.

In addition to the observed preferences of physical characteristics, the females in this study showed preferences for tree species from three different plant families while they avoided those of three other families. Preferences for particular tree species or plant families have been reported for a number of mammals (Cockburn \& Lazenby-Cohen 1992; Sedgeley \& O'Donnell 1999; Kunz \& Lumsden 2003; Smith et al. 2007) and have been linked to the size and probability of occurrence of tree cavities (Gibbons \& Lindenmayer 2002). Such information is lacking for the tree families in our study area and although these factors are likely to play a role we cannot make similar conclusions from the present data. Nevertheless, the discrepancy between physical and family properties of trees with tree holes used and those found in the study area indicate that their availability is restricted. In the light of the potential benefits female grey mouse lemurs can derive from sleeping sites, this is likely to impact significantly on female survival and reproductive success in the study species. In contrast, there should be fewer constraints on the availability of nest and open sites and in bats it has been repeatedly suggested that foliage for roosting is not limited (Kunz 1982; Kunz \& Lumsden 2003; Kerth 2008). However, this assumption ignores potential temporal variation in the availability of foliage. Female grey mouse lemurs build nests from leaves that are only found on trees during the wet season and this may partly account for the seasonal shift in sleeping site usage. At the same time, tree holes may not be usable after the heavy downpours common during the wet season as they fill up with water (H. Lutermann, personal observation). This could further limit the availability of suitable sites particularly for breeding females.

\section{Conclusions}

In the study population sleeping site choices appear to be governed by thermoregulatory demands and site availability. This poses strong selection pressures on females to adopt strategies that provide access to such resources for survival and reproduction. In accordance with mechanisms suggested for other species (Kunz 1982; Du Plessis 1992; Kunz \& Lumsden 2003; Walker et al. 2007; Kerth 2008) this could be achieved by forming groups with close kin (Lutermann et al. 2006). Indeed grey mouse lemur females are frequently found in kin groups at their sleeping sites (Radespiel et al. 2001). However, female grey mouse lemur groups are usually small and this may be related to both the space limitations of the available sleeping sites and costs associated with social grouping ( $\mathrm{H}$. Lutermann, unpublished data). Our results suggest that studies of sleeping sites and shelters in small mammals can provide important insights into their ecology and social system.

\section{Acknowledgments}

We thank the Commission Tripartite of the Malagasy government and the DEF, the ANGAP and $\mathrm{CI}$ for the permission to work in Ampijoroa. The research carried out was in compliance with the 
laws in Madagascar. We are indebted to the late Professor B. Rakotosamimanana (University of Antananarivo), Blanchard Randrianambinina and Solofo Rasoloharijaona for the institutional help and logistic support. This study was funded by the DAAD (HSP II to H.L.) and the German Research Council (DFG). We are grateful to Jeannine Raharilala and Franck Rakotonasolo from Parc Botanique and Zoologique Tsimbazaza, Antananarivo, Madagascar for plant identification. We are indebted to the staff of the Angonoka Breeding station of the Durrell Wildlife Conservation Trust, Jersey, Channel Islands, U.K. in Ampijoroa who generously shared their weather data and a number of volunteers that participated in the project.

\section{References}

Ardia, D. R., Perez, J. H. \& Clotfelder, E. D. 2006. Nest box orientation affects internal temperature and nest site selection by tree swallows. Journal of Ornithology, 77, 339-344.

Chaverri, G., Quirós, O. E., Gamba-Rios, M. \& Kunz, T. H. 2007a. Ecological correlates of roost fidelity in the tent-making bat Artibeus watsoni. Ethology, 113, 598-605.

Chaverri, G., Gamba-Rios, M. \& Kunz, T. H. 2007b. Range overlap and association patterns in the tent-making bat Artibeus watsoni. Animal Behaviour, 73, 157-164.

Clutton-Brock, T. H. 1989. Mammalian mating systems. Proceedings of the Royal Society B, 236, 339-371.

Cockburn, A. \& Lazenby-Cohen, K. A. 1992. Use of nest trees by Antechinus stuartii, a semelparous lekking marsupial. Journal of Zoology, 226, 657-680.

Day, R. T. \& Elwood, R. W. 1999. Sleeping site selection by the golden-handed tamarin Saguinus midas midas: the role of predation risk proximity to feeding sites and territorial defence. Ethology, 105, 1035-1051.

Di Bitteti, M. S., Vidal, E. M. L., Baldovino, M. C. \& Benesovsky, V. 2000. Sleeping site preferences in tufted capuchin monkeys. American Journal of Primatology, 50, 257-274.

Doncaster, C. P. \& Woodroffe, R. 1993. Den site can determine shape and size of badger territories: implications for group-living. Oikos, 66, 88-93.

Du Plessis, M. A. 1992. Obligate cavity-roosting as a constraint on dispersal of green (red-billed) woodhoopoes: consequences for philopatry and the likelihood of inbreeding. Oecologia, 90, 205-211.

Elgar, M. A., Pagel, M. D. \& Harvey, P. H. 1988. Sleep in mammals. Animal Behaviour, 36, $1409-1419$.

Emlen, S. T. \& Oring, L. W. 1977. Ecology sexual selection and the evolution of mating systems. Science, 197, 215-223.

Fisher, R. J. \& Wiebe, K. L. 2006. Nest site attributes and temporal patterns of northern flicker nest loss: effects of predation and competition. Oecologia, 147, 744-753.

Ganzhorn, J. U. \& Schmid, J. 1998. Different population dynamics of Microcebus murinus in primary and secondary deciduous dry forests of Madagascar. International Journal of Primatology, 19, 785-796.

Geiser, F. 1994. Hibernation and daily torpor in marsupials: a review. Australian Journal of Zoology, 42, 1-16.

Gibbons, P. \& Lindenmayer, D. B. 2002. Tree Hollows and Wildlife. Conservation in Australia. Collingwood: CSIRO.

Henner, C. M., Chamberlain, M. J., Leopold, B. D. \& Burger, L. W. 2004. A multiresolution assessment of raccoon den selection. Journal of Wildlife Management, 68, 179-187.

Isaac, J. L., De Gabriel, J. L. \& Goodman, B. A. 2008. Microclimate of daytime den sites in a tropical possum: implications for the conservation of tropical arboreal marsupials. Animal Conservation, 11, 281-287.

Kerth, G., Weissmann, K. \& König, B. 2001. Day roost selection in female Bechstein's bats (Myotis bechsteinii): a field experiment to determine the influence of roost temperature. Oecologia, 126, 1-9.

Kerth, G. 2008. Causes and consequences of sociality in bats. Bioscience, 38 , 737-746.

Kunz, T. H. 1982. Roosting ecology of bats. In: Ecology of Bats (Ed. by T. H. Kunz), pp. 1-55. New York: Plenum.

Kunz, T. H. \& Lumsden, L. F. 2003. Ecology of cavity and foliage roosting bats. In: Bat Ecology (Ed. by T. H. Kunz \& M. B. Fenton), pp. 3-89. Chicago: University of Chicago Press.

Lahann, P. 2008. Habitat utilization of three sympatric cheirogaleid lemur species in a littoral rain forest of southeastern Madagascar. International Journal of Primatology, 29, 117-134.

Lausen, C. L. \& Barclay, R. M. R. 2003. Thermoregulation and roost selection by reproductive big brown female bats (Eptesicus fuscus) roosting in rock crevices. Journal of Zoology, 260, 235-244.

Lindenmayer, D. B., Pope, M. L. \& Cunningham, R. B. 2004. Patch use by the greater glider (Petauroides volans) in a fragmented forest ecosystem. II. Characteristics of den trees and preliminary data on den-use patterns. Wildlife Research, 32, 569-577.
Lutermann, H., Schmelting, B., Radespiel, U., Ehresmann, P. \& Zimmermann, E. 2006. The role of survival for the evolution of female philopatry in a solitary forager the grey mouse lemur (Microcebus murinus). Proceedings of the Royal Society B, 273, 2527-2533.

Maher, C. R. \& Lott, D. F. 2000. A review of ecological determinants of territoriality within vertebrate species. American Midland Naturalist, 143, 1-29.

Martin, J. K. \& Martin, A. A. 2007. Resource distribution influences mating system in the bobuck (Trichosurus cunninghami: Marsupialia). Oecologia, 154, 227-236.

Martin, R. D. 1973. A review of the behaviour and ecology of the lesser mouse lemur (Microcebus murinus). In: Comparative Ecology and Behaviour of Primates (Ed. by R. P. Michael \& J. H. Crook), pp. 1-68. London: Academic Press.

Mittermeier, R. A., Ganzhorn, J. U., Konstant, W. R., Glander, K., Tattersall, I., Groves, C. P., Rylands, A. B., Hapke, A., Ratsimbazafy, J., Mayor, M. I., Louis, E. E. Jr., Rumpler, Y., Schwitzer, C. \& Rasoloarison, R. 2009. Lemu diversity in Madagascar. International Journal of Primatology, 29, 1607-1656.

Ostfeld, R. S. 1985. Limiting resources and territoriality in microtine rodents. American Naturalist, 126, 1-15.

Ostfeld, R. S. 1990. The ecology of territoriality in small mammals. Trends in Ecology E Evolution, 5, 411-415.

Radespiel, U., Cepok, S., Zietemann, V. \& Zimmermann, E. 1998. Sex-specific usage patterns of sleeping-sites in grey mouse lemurs. American Journal of Primatology, 46, 77-84.

Radespiel, U., Sarikaya, Z., Zimmermann, E. \& Bruford, M. W. 2001. Socio-genetic structure in a free-living nocturnal primate population sex-specific differences in the grey mouse lemur (Microcebus murinus). Behavioral Ecology and Sociobiology, 50, 493-502.

Radespiel, U., Ehresmann, P. \& Zimmermann, E. 2003. Species-specific usage of sleeping sites in two sympatric mouse lemur species (Microcebus murinus and M. ravelobensis) in Northwestern Madagascar. American Journal of Primatology, 59, 139-151.

Rendigs, A., Radespiel, U., Wrogemann, D. \& Zimmermann, E. 2003. Relationship between microhabitat characteristics and distribution of mouse lemurs (Microcebus spp) in Northwestern Madagascar. International Journal of Primatology, 24, 47-64.

Rice, W. R. 1989. Analysing tables of statistical tests. Evolution, 43, 223-225.

Rogers, L. M., Forrester, D. J., Wilson, G. J., Yarnell, R. W. \& Cheeseman, C. L. 2003. The role of setts in badger (Meles meles) group size, breeding success and status of TB (Mycobacterium bovis). Journal of Zoology, 260, 209-215.

Roper, T. J. 1992. The structure and function of badger setts. Journal of Zoology, 227, 691-698.

Roper, T. J., Bennett, N. C., Conradt, L. \& Molteno, A. J. 2001. Environmenta conditions in burrows of two species of African mole-rat Georhychus capensis and Cryptomys damarensis. Journal of Zoology, 254, 101-107.

van Schaik, C. P. 1989. The ecology of social relationships amongst female primates In: The Behavioural Ecology of Humans and Other Mammals (Ed. by V. Standen \& R. A. Foley), pp. 195-218. Oxford: Blackwell Scientific

Schmelting, B., Ehresmann, P., Lutermann, H., Randrianambinina, B. \& Zimmermann, E. 2000. Reproduction of two sympatric mouse lemurs (Microcebus murinus and $M$. ravelobensis) in north-west Madagascar: first results of a long term study. In: Diversité et Endémisme à Madagascar (Ed. by W. R. Lourenco \& S. M. Goodman), pp. 1-12. Paris: Sociéte de Biogeographie.

Schmid, J. 1998. Tree holes used for resting by gray mouse lemurs (Microcebus murinus) in Madagascar: insulation capacities and energetic consequences. International Journal of Primatology, 19, 797-809.

Schmid, J. 2000. Daily torpor in the gray mouse lemur (Microcebus murinus) in Madagascar: energetic consequences and biological significance. Oecologia, 123 175-183.

Schmid, J. \& Speakman, J. R. 2000. Daily energy expenditure of the grey mouse lemur (Microcebus murinus): a small primate that uses torpor. Journal of Comparative Physiology B, 170, 633-641.

Schmidt-Nielsen, K. 1997. Animal Physiology: Adaptation and Environment. Cambridge: Cambridge University Press.

Sedgeley, J. A. 2001. Quality of cavity microclimate as a factor influencing selection of maternity roosts by a tree-dwelling bat Chalinolobus tuberculatus in New Zealand. Journal of Applied Ecology, 38, 425-438.

Sedgeley, J. A. \& O'Donnell, C. F. J. 1999. Factors influencing the selection of roos cavities by a temperate rainforest bat (Vespertilioniedae: Chalinolobus tuberculatus) in New Zealand. Journal of Zoology, 249, 437-446.

Smith, G. C., Mathieson, M. \& Hogan, L. 2007. Home range and habitat use of a low-density population of greater gliders, Petauroides volans (Pseudocheiridae: Marsupialia), in a hollow-limiting environment. Wildlife Research, 34 $472-483$.

Soderquist, T. R. 1993. Maternal strategies of Phascogale tapoatafa (Marsupialia Dasyuridae): juvenile thermoregulation and maternal attendance. Australian Journal of Zoology, 41, 567-576.

Solick, D. I. \& Barclay, R. M. R. 2007. Geographic variation in use of torpor and roosting behaviour of female western long-eared bats. Journal of Zoology, 272 358-366.

Speakman, J. R., Irwin, N., Tallach, N. \& Stone, R. 1999. Effect of roost size on the emergence behaviour of pipistrelle bats. Animal Behaviour, 58, 787-795.

Sterck, E. H. M., Watt, P. \& van Schaik, C. P. 1997. The evolution of female social relationships in nonhuman primates. Behavioral Ecology and Sociobiology, 41, 291-309.

Tattersall, I. 1982. The Primates of Madagascar. New York: Columbia University Press. 
Thorén, S., Quietzsch, F. \& Radespiel, U. 2010. Leaf nest use and construction in the golden-brown mouse lemur (Microcebus rabelobensis) in the Ankarafantsika National Park. American Journal of Primatology, 72, 48-55.

Velky, M., Kanuch, P. \& Kristin, A. 2010. Selection of winter roosts in the great tit Parus major: influence of microclimate. Journal of Ornithology, 151, 147-153.
Walker, F. M., Taylor, A. C. \& Sunnucks, P. 2007. Does soil type drive social organization in southern hairy-nosed wombats? Molecular Ecology, 16, 199-208.

Willis, C. K. R. \& Brigham, R. M. 2007. Social thermoregulation exerts more influence than microclimate on forest roost preferences by a cavity-dwelling bat. Behavioral Ecology and Sociobiology, 62, 97-108.

Please cite this article in press as: Lutermann, H., et al., Resting and nesting in a small mammal: sleeping sites as a limiting resource for female grey mouse lemurs, Animal Behaviour (2010), doi:10.1016/j.anbehav.2010.02.017 